\title{
Communications
}

\section{Mild and Efficient Debromination of vic-Dibromides to Alkenes with $\mathrm{NiCl}_{2} \cdot 6 \mathrm{H}_{2} \mathrm{O} /$ Indium System}

\author{
Byung Woo Yoo, Jin Woo Choi, and Ye Seul Kim \\ Department of Advanced Materials Chemistry, Korea Chiversitv, Jochin' Chungnam 339-700, Korea \\ E-mail: bryoorikoreacackr \\ Received Aprit 28, 2008
}

Key Words : Debromination. Alkene. Nickel chloride. Indium

The debromination of $v i c$-dibromides to alkenes is important in organic synthesis as a double bond protectiondeprotection strategy. 'Although reductive debromination of vic-dibromides with various agents has been the subject of many reports. some of these methods are associated with limitations regarding low yields, prolonged reaction times. and harsh reaction conditions. 2 Consequently an efficient and mild procedure for debromination of vic-dibromides continues to be developed. The chenical reactivity of $\mathrm{NiCl} /$ $\mathrm{M}$ system $(\mathrm{M}=\mathrm{Zn}, \mathrm{Al}$. Sm) has been the subject of considerable interest and the reducing ability of these systems has been extensively studied. ${ }^{3}$ Because of the close resemblance of indium to zinc in several respects, including first ionization. we considered that $\mathrm{NiCl}_{2} 6 \mathrm{H}_{2} \mathrm{O} / \mathrm{In}$ system could also be a useful addition to the conventional method. Recently. indium metal has drawn an increasing attention for its unique properties such as low toxicity and high stability in water and air compaired with other metals. ${ }^{4}$

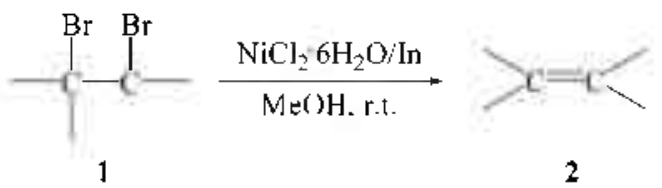

In continuation of our efforts towards the development of the low-valent metal reagents for organic transformations, we wish to report a mild and efficient procedure for debromination of vic-dibronides 1 to the corresponding alkenes 2 with $\mathrm{NiCl}_{2} \cdot 6 \mathrm{H}_{2} \mathrm{O} / \mathrm{In}$ system in methanol at room temperature. The reaction can be generalized as in eq. (1). ${ }^{\circ}$ The new reagent system was generated by the addition of indium powder to a stirred solution of nickel chloride hexahy'drate in methanol under sonication. ${ }^{7}$ We have investigated the reactions of $\mathrm{NiCl}_{2} \cdot 6 \mathrm{H}_{2} \mathrm{O} / \mathrm{h}$ system with various vicdibromides and observed that the debrominations generally proceeded with high yields and good selectivity over other labile substituents. Some control experiments revealed that vic-dibromides could not be debrominated by nickel chloride hexalyydrate or indium alone under the reaction conditions. The high yields of the debromination products demonstrate the efficiency of this new method. A $2: 1$ ratio of indium and $\mathrm{NiCl}_{2} \cdot 6 \mathrm{H}_{2} \mathrm{O}$ was the best ratio in terms of $y$ ield and reaction time. And methanol has been found to be the most suitable solvent for the reaction. The result of this reduction is summarized in Table 1 . where we examined a series of functionally and sterically diverse vic-dibromides.

Table 1. Reductive debromination of vic-dibromides with $\mathrm{NiCl}_{2} \cdot 6 \mathrm{H}_{2} \mathrm{O}$ In system

Entry

asclated yields. 


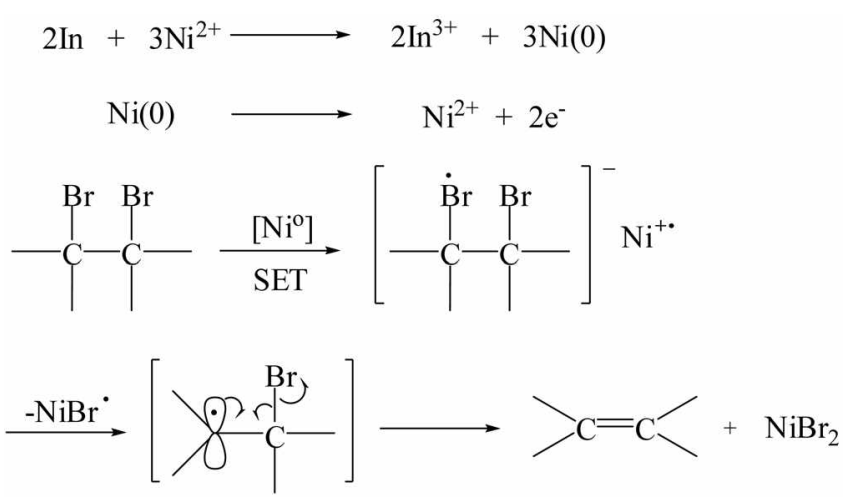

Scheme 1

Clearly a broad range of functional groups (ester. acid. aldehyde. methosy, chloro. and ketone) was tolerated under the reaction conditions and only trans olefins were obtained. There was no evidence for the formation of any overreduction product. The formation of the reduced products can be conceived to proceed via alkenes by debromination of the dibronides and subsequent reduction as Khurana has suggested in his work. ${ }^{8}$ In comparison with other procedures. the present procedure reduces $v i c$-dibromides in higher yields and showed a good chemoselectivity under mild conditions. The notable advantages of this methodology are mild reaction conditions, simple manipulation. high yields, and tolerance of various functional groups. All the compounds obtained showed IR, NMR and mass spectral data compatible with the structure. Some of the $v i c$ dibromides in the table are conumercially available, or could be prepared conveniently from the corresponding precursors through known olefin halogenation reactions. ${ }^{9}$ Although the reaction mechanism is still unclear, the reaction can be envisaged to proceed in two stages. In the first, nickel(II) chloride is probably reduced by indium to form low-valent nickel species. which in the subsequent step would debrominate $v i c$-dibromides 1 to give the corresponding alkenes 2 through a SET (single electron transfer) process (Scheme 1). The reducing property exihibited by metalmetal salt combinations proceeds through transfer of one electron from the metal surface to the substrate. In such combinations elementary metal part needs to be more electropositive than the metal part of the salt. ${ }^{11)}$ We have been able to demonstrate the utility of $\mathrm{NiCl}_{2} \cdot 6 \mathrm{H}_{2} \mathrm{O}$ /indium system for effecting chemoselective debromination of $v i c$. dibromides.

In conclusion. we have discovered that $\mathrm{NiCl}_{2} \cdot 6 \mathrm{H}_{2} \mathrm{O} / \mathrm{In}$ system mediates an efficient and mild conversion of vicdibromides to the corresponding alkenes with high yields.
Although the scope and limitations were not fully established, the present method could be a practical alternative to the conventional methods.

Acknowledgments. This work was supported by the Brain Korea 21 project in 2008.

\section{References}

1. (a) For a review. see Tatesh. A. M.: Weiguny. T. Chem. Rev 1996. 96. 2035. (b) Green. T. W. Wuts. P. G. M. Protective Gontps in Organic Swmhesis. 2nd ed.: New York. 1991

2. (a) Buther. T. S.; Dett: M. R. J. Org. Chem. 1998. 63, 177. (b) Li. C. J.: Harpp. D. N. Tetrahedron Lett. 1990, 31.6291. (c) Malanga. C.: Mannucci, S.; Lardicci, L. Tetrahedron 1998. 5t, 1021. (d) Tanata. R.: Negoro. N.: Yanada. K.: Fujita. T. Tetrohedron Lett. 1996. 37. 9313. (e) Ranu. B. C.: Guchhait. S. K.: Sarkar. A. J. Chent. Soc. Chen Connm 1998. 2113. (f) Mathai. 1. M.: Sching, K.: Miller, S. I. J. Org. Chm. 1970. 35. 1733.

3. (a) Raju. B. R.; Devi. G.: Nongpluh, Y. S.; Saika, A. K. Synlett 2005. 2. 358. (b) Bezbarua. M. S.: Bez. G; Baru. N. C. Chem. Lett. 1999. 325. (c) Petrier. C.: Luche. T.-L. Tetrahedron Lett. 1987. 28. 2351. (d) Wu. H.: Chent. R.: Zhang. Y. Smmt. Conmum. 2002. 32. 189

4. For reviews see: (a) Li. C. J. Chem Ron 1993, 93,2 (123. (b) Lubineau, A.: Auge. J:: Queneau, Y. Symhesis 1994, 741. (c) Li. C. J. Tetrahedron 1996. 52. 5643. (d) Cintas. P. Sylett 1995, 1087.

5. (a) Han. J. H.: Choi. K. I.: Kim. T. H.: Yoon. C. M.: Yoo. B. W. Smth. Commm. 2006. 36.415. (b) Yoo. B. W. Song. M. S.: Park. M. C. Swm. Conmm 2007. 37. 3089. (c) Han. J. H.: Choi. J. W.: Choi. K. I.; Kim. J. H.; Yoo. B. W. Bull Kowan Chem. Soc. 2006. 27. 1115. (d) Choi. K. H: Choi, K. I.; Kim, J. H.: Yoon. C. M: Yoo, B. W. Bull. Korean Chem. Soc. 2005, 26. 1495, (e) Yoo. B. W. Song. M. S.: Park. M. C. Bull. Korean Chent Soc. 2007. 28. 171.

6. A typical procedure tor the debromination of vic-dibromides is as follows: Indium powder (230 mg. $2.0 \mathrm{mmmol}$ ). and nickel( $(\square)$ chloride hexahydrate $(238 \mathrm{mg} .1 .0 \mathrm{mmol}$ ) were mixed in methanol $(4 \mathrm{~mL}$ ). The resulting mixture was stirred at room temperature tor $0.5 \mathrm{hr}$ under sonication to get a solution of the low-valent nichelindium comples. 1.2-Dibro-moethylbenzene (264 mg. $1.0 \mathrm{mmol}$ ) was then added to this solution and the reaction misture was stirred for 30 minl. at room temperature. The solvent was removed under reduced pressure and the residue was extracted with ether, washed with brine. and dried over anhydrous $\mathrm{Na}_{2} \mathrm{SO}_{4}$. The crude product was purified by silica gel column chromatography (hexane:ethyl acetate $=10: 1)$ to aftord styrene $\left(99 \mathrm{mg} .95^{\circ} \circ\right.$ ). Ail of the products are commercially available compounds. and their identification was based on spectral comparison with authentic samples.

7. Sonication were carried out in a BRANSONIC ultrasonic cleaner bath. which delivered a $47 \mathrm{kHz}$ wave, with a fixed electrical power of 125 Watts.

8. Khurana. T. M.: Gogia. A.: Bankhwal. R. K. Sinth. Conmum. 1997. 27. 1801

9. Iogel's Textbook of Practical Organic Chemistry the ed: New York. USA. 1978; 400

10. Mourad, M. S.: Verma. R. S.; Kabalka, G. W. J. Org. Chem. 1985. 50.133. 